\title{
Mobile Web-based Education: Engagement and Satisfaction with HiChart among Pregnant Women
}

\author{
Hyo Jin Kim ${ }^{1}$, Hee Sun Kang ${ }^{2}$ \\ ${ }^{1}$ Graduate Student, Red Cross College of Nursing, Chung-Ang University, Seoul; ${ }^{2}$ Professor, Red Cross College of Nursing, Chung-Ang University, Seoul, Korea
}

Purpose: This study aimed to examine engagement and satisfaction with a mobile web-based education program (HiChart) among pregnant women. Methods: A cross-sectional descriptive study was conducted of 97 pregnant women hospitalized for obstetric care. Data were collected from October 1 to November 30, 2016, and were analyzed with descriptive statistics. Results: Among participants, $16.5 \%$ engaged fully with HiChart, while $43.3 \%$ engaged partially. The overall satisfaction with HiChart was high. Some main reasons for not engaging with the education were participants' unawareness of the text messages, lack of time, and poor internet connection. The participants suggested that more educational content needed to be covered, such as coping with infant emergencies and information about the neonatal intensive care unit. Conclusion: To increase pregnant women's engagement with mobile web-based education, efforts are needed to strengthen the system of sending text messages as part of mobile web-based education to all patients, to inform pregnant women that an educational web link was sent, and to encourage them to engage with mobile web-based education. Furthermore, it is essential to improve the HiChart service by providing educational content corresponding to users' needs.

Key words: Smartphone; Pregnant women; Prenatal education; Personal satisfaction

\section{Corresponding author Hee Sun Kang https://orcid.org/0000-0003-3808-306X}

Red Cross College of Nursing, Chung-Ang University, 84 Heukseok-ro, Dongjak-gu, Seoul 06974, Korea

TEL +82-2-820-5699 FAX +82-2-824-7961

E-MAIL goodcare@cau.ac.kr

*This article was adapted from a thesis by Hyo Jin Kim in partial fulfillment of the requirements for the master's degree at Chung-Ang University.

Received Mar 12, 2019 Revised May 24, 2019 Accepted Jun 10, 2019

(a) This is an Open Access article distributed under the terms of the Creative Commons Attribution NonCommercial License (http://creativecommons.org/licenses/by-nc/4.0/) which permits unrestricted noncommercial use, distribution, and reproduction in any medium, provided the original work is properly cited.

\section{INTRODUCTION}

Pregnant women have a high demand for education regarding various pregnancy-related topics such as medication during pregnancy, vaginal delivery and cesarean sections, management of the puerperium, and breast care and breastfeeding [1-3]. Despite their high need for education, the prenatal class attendance rate is low. Because most prenatal education programs are presented in group lectures at specific time and locations, the greatest barriers preventing pregnant women from participating in prenatal education programs are having insufficient time and not being aware of the prenatal education location $[2,4]$. Adequate prenatal education helps pregnant women to improve their self-management skills, have more confidence in maintaining a healthy pregnancy, prevent pregnancy-related complications, and reduce their anxiety [5,6]. Other positive expected effects of education include reduced stress and increased self-efficacy [7]. Since the educational needs of individual pregnant women differ, providing adequate education tailored to individual characteristics is necessary.

As the use of smart devices such as smartphones is growing in popularity, online learning without restrictions of space and time has become an opportunity to enhance education [8]. 
It has been reported that pregnant women use the internet and smartphone applications (apps) as a source of information during pregnancy [9-12]. A study of 335 Chinese pregnant women showed that the internet was a common source of pregnancy-related information [9]. Similarly, a systematic review of the internet use of pregnant women reported that women used the internet as a source of information, especially regarding fetal development and nutrition during pregnancy [10]. Additionally, a study on pregnancy-related app usage in 193 pregnant women reported that $55 \%$ of the participants used mobile apps related to pregnancy, birth, and/or childcare, and the most frequently accessed information was about the signs of risk and disease during pregnancy [11]. Regarding text messages, a study conducted in 20 public primary health care units with a total of 1,210 pregnant women showed that women who received and read all short text messages related to pregnancy and childbirth had significantly higher rates of engagement in antenatal care practices, including antenatal visits, than those who received routine care [13]. Furthermore, the text messages acted as a source of positive motivation and were perceived as extended care from the health care provider [14]. Education using the "Pregnant with Diabetes" app was effective for improving pregnancy planning and outcomes in women with diabetes [15], and education using an app on pregnancy-related health and nutrition information was effective for increasing women's self-confidence in the management of gestational diabetes mellitus and their motivation for behavioral change [16]. These findings indicate that an easily accessible app education program may positively impact pregnant women's health. A systematic review of 14 studies reported that mobile health (mHealth) interventions were effective at improving antenatal and postnatal care services, and especially at changing the behavior of pregnant and postpartum women [17]. However, those studies were mainly conducted in the outpatient setting before admission and little evidence exists on mobile web-based education services for inpatient pregnant women.

The traditional education method involves a nurse directly guiding hospitalized pregnant women using brochures or booklets. However, electronic health (eHealth) or mHealth education is currently being used at hospitals. The HiChart educational materials were developed based on previous educational resources to promote the patients' understanding of and satisfaction with audiovisual education materials. Studies have reported that mobile education was well accepted by inpatients and could enhance a patients' knowledge and self-care participation $[18,19]$.

Mobile web-based education for hospitalized pregnant women can provide tailored education according to pregnancy status and reasons for admission. Although nurses send links to mobile web-based education to hospitalized pregnant women at the hospital where this study was conducted, pregnant women's actual engagement and degree of satisfaction with mobile web-based education have not been evaluated. This study aimed to examine (1) participants' engagement with the mobile web-based education program (HiChart), (2) their reasons for not engaging with the materials they received, and (3) their satisfaction with mobile web-based education.

\section{METHODS}

\section{Study Design and Sample}

This study employed a cross-sectional descriptive design. The study participants were 97 pregnant women who had smartphones and were admitted for obstetrical care to $S$ Medical Center, a tertiary medical center in Seoul, South Korea.

\section{Mobile Web-based Education Program (HiChart)}

In this study, the mobile web-based education program was HiChart, an education program comprising animated videos (HiChart ${ }^{\circledR}$, Health Breeze, Korea) in five categories:(1) hospitalization (admission), (2) delivery, (3) postpartum care, (4) newborn care, (5) high- risk pregnancies, and (5) discharge (Table 1) (Figure 1).

The HiChart development process was as follows. Based on educational materials in the form of brochures previously used by hospitalized pregnant women, various scenarios were portrayed in the form of animated educational videos. The HiChart app for pregnant women was developed after meetings with healthcare information team developers and Health Breeze staff. After reviewing and revising the education program with a group of experts, it was finalized as a mobile webbased education program for pregnant women.

At present, at the hospital where this study was conducted, a nurse sends text messages that contain web links to HiChart animated videos to the smartphones of all hospitalized pregnant women as part of routine nursing care on the day of admission, immediately after delivery, and before discharge. On the day of admission, a nurse sends a text message with a web link to the educational material on admission and delivery based on their delivery mode (induced labor or cesarean section), and sends a link to the material on high-risk pregnancies to high-risk pregnant women. Immediately after delivery, a nurse sends text message(s) related to postpartum care and newborn care in the afternoon of the day before discharge, and sends a link to materials on discharge education in the evening of that day. 


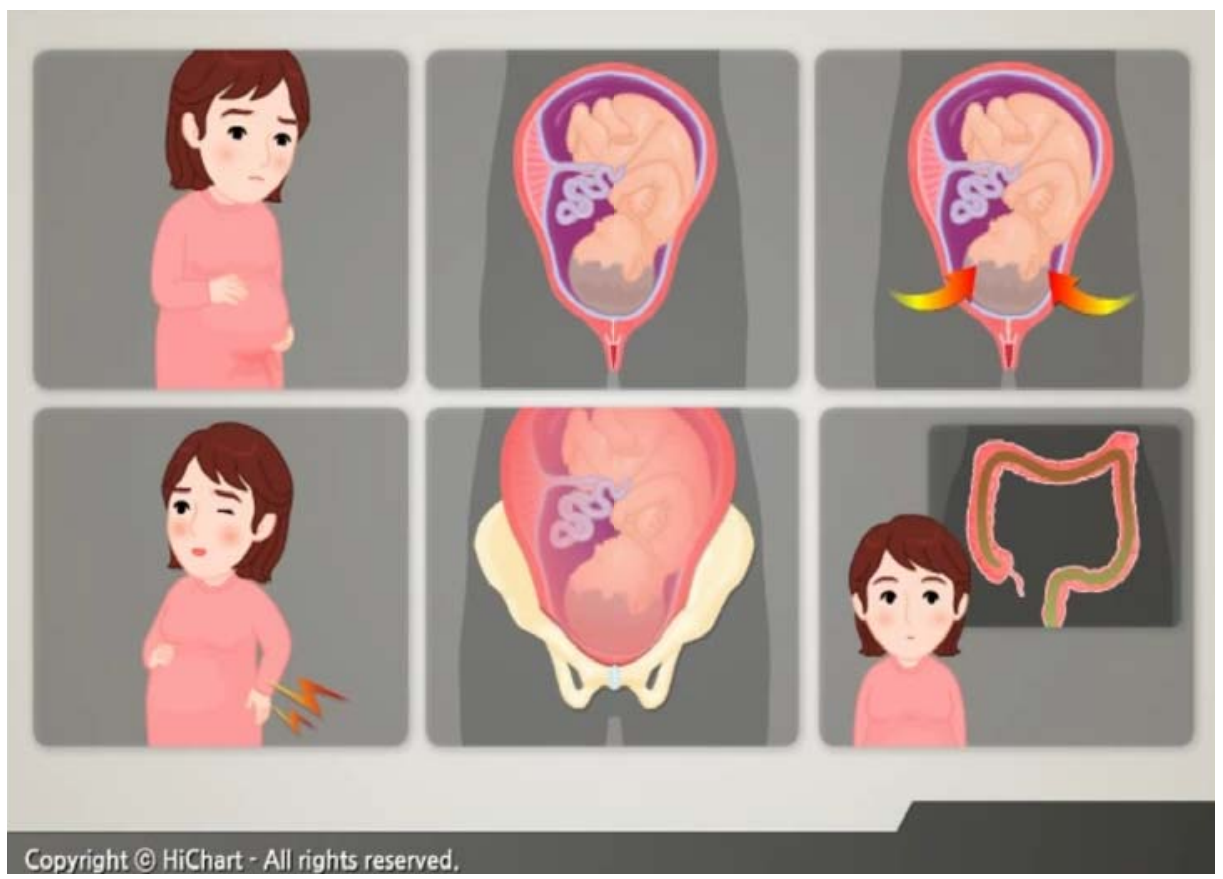

Figure 1. Sample image of the HiChart video screen (discharge education for preterm labor patients).

Table 1. Content of the HiChart Mobile Web-based Education Program

\begin{tabular}{|c|c|c|c|}
\hline Categories & Contents & $\begin{array}{l}\text { Running time } \\
\text { (min) }\end{array}$ & Message sent \\
\hline $\begin{array}{l}\text { Hospitalization } \\
\text { (admission) }\end{array}$ & $\begin{array}{l}\text { Hospitalization guide } \\
\text { Fall prevention guide } \\
\text { Anti-embolism stocking guide for pregnant woman }\end{array}$ & $\begin{array}{r}17: 08 \\
6: 24 \\
3: 02\end{array}$ & $\begin{array}{c}\text { On } \\
\text { admission }\end{array}$ \\
\hline Delivery & $\begin{array}{l}\text { Labor induction patient information } \\
\text { Cesarean section patient information }\end{array}$ & $\begin{array}{l}3: 44 \\
9: 35\end{array}$ & $\begin{array}{c}\text { On } \\
\text { admission }\end{array}$ \\
\hline Postpartum care & $\begin{array}{l}\text { Couplet care } \\
\text { Breastfeeding guide }\end{array}$ & $\begin{array}{l}9: 40 \\
6: 03\end{array}$ & $\begin{array}{c}\text { After } \\
\text { delivery }\end{array}$ \\
\hline Newborn care & $\begin{array}{l}\text { Nursery room guide } \\
\text { Normal delivery newborn baby's schedule } \\
\text { Cesarean section newborn baby's schedule } \\
\text { Neonatal screening information } \\
\text { Guide for newborn care after discharge }\end{array}$ & $\begin{array}{l}3: 49 \\
2: 59 \\
4: 16 \\
4: 28 \\
8: 56\end{array}$ & $\begin{array}{c}\text { After } \\
\text { delivery }\end{array}$ \\
\hline $\begin{array}{l}\text { High risk } \\
\text { pregnancies }\end{array}$ & $\begin{array}{l}\text { Hospitalization guide for high-risk pregnant women } \\
\text { Bedside exercise program: Neck } \\
\text { Bedside exercise program: Arms } \\
\text { Bedside exercise program: Legs } \\
\text { Cervical cerclage patient information (McDonald's OP) } \\
\text { Pregnancy induced hypertension guide } \\
\text { Glycemic control and insulin injection guide for gestational diabetes mellitus }\end{array}$ & $\begin{array}{l}5: 00 \\
4: 31 \\
9: 41 \\
7: 09 \\
4: 19 \\
5: 47 \\
7: 35\end{array}$ & $\begin{array}{c}\text { On } \\
\text { admission }\end{array}$ \\
\hline Discharge & $\begin{array}{l}\text { Discharge education for vaginal delivery patients } \\
\text { Discharge education for cesarean section patients } \\
\text { Discharge education for preterm labor patients }\end{array}$ & $\begin{array}{r}10: 01 \\
8: 18 \\
3: 47\end{array}$ & $\begin{array}{l}\text { Evening of } \\
\text { the day before } \\
\text { discharge }\end{array}$ \\
\hline
\end{tabular}




\section{Measurements}

This study used a structured questionnaire consisting of general and obstetric characteristics, engagement and reasons for non-engagement, and satisfaction related to the mobile web-based education program (HiChart). The questionnaire was developed after conducting a literature reviews [20-22] and was validated by experts in obstetrics, including a professor of obstetrics and gynecology, a head nurse of an obstetrical ward, a nurse with a doctorate in nursing and over 10 years of experience in obstetrics and gynecology, and two nurses who had worked in an obstetric ward for more than 5 years. The content validity index for all the questions was above .80 .

\section{1) Engagement}

Engagement was measured by a one-item self-report on whether the participant had viewed the mobile web-based education program (HiChart) through the web link (URL) provided by the nurse. Engagement was categorized as complete (viewed all), partial (viewed in part), or none.

\section{2) Reasons for non-engagement}

Reasons for not engaging with HiChart were measured with binary (yes or no) responses. In addition, we asked participants to describe other reasons they had that were not addressed by those eight specific items. The items were as follows: (1) they had an internet connection problem, (2) their smartphone battery was low, (3) the educational material was too long and boring, (4) they already knew the educational content, (5) they did not need it (education), (6) they did not have enough time to watch it, (7) they did not know what the text message was for, (8) they thought the text message was spam, and (9) other reasons.

\section{3) Satisfaction}

Participants' satisfaction with HiChart was measured using four items including overall satisfaction, ease of understanding, sufficiency of the information, and convenience. Each item was rated on a 5-point Likert scale ranging from "strongly disagree" (scored as 1) to "strongly agree" (scored as $5)$, with higher scores indicating greater satisfaction. For this study, the Cronbach's $\alpha$ coefficient of the satisfaction scale was .86.

\section{Data Collection}

Data were collected using a self-report questionnaire. The survey was conducted in the morning of the discharge day of the hospitalized pregnant women considering that the Hi-
Chart massages had been sent on the day of admission, after delivery, and the day before discharge. The questionnaires were administered after the purpose and methods of the study were explained by the researcher and written consent was obtained from women who agreed to participate in the study. Participants were assured of anonymity and confidentiality and informed they were free to withdraw at any time.

In all, 100 pregnant women agreed to participate in this study, and 97 completed questionnaires were analyzed, after three incomplete questionnaires were excluded. The survey took 10 minutes to complete and no identifiable information was recorded to protect patient privacy. The data were collected from October to November 2016.

\section{Ethical Considerations}

This study was approved by the Institutional Review Board of S Medical Center (2016-09-131-004). All participants were informed about the purpose of this study and participants' right to withdraw from the study at any time. Confidentiality of participants was ensured and written informed consent was obtained from each participant.

\section{Data Analysis}

Data were analyzed using SPSS version 22.0 (IBM Corp., Armonk, NY, USA) with descriptive statistics including frequency, percentage, mean and standard deviation, and content analysis for open-ended questions. Statistical differences between groups were analyzed using the t-test, analysis of variance, or the $x^{2}$ test.

\section{RESULTS}

\section{Demographic and Obstetric Characteristics of Partici- pants}

The demographic and obstetric characteristics of participants are summarized in Table 2. The mean age of participants was $33.4 \pm 4.0$ years. The mean gestational age of participants was $36.5 \pm 4.6$ weeks, and $72.2 \%$ of participants had a gestational age of more than 37 weeks. Women giving birth for the first time (primipara women) accounted for $56.7 \%$ of the respondents.

\section{Engagement}

Among the education categories, admission (71.5\%) was the most common type of text message sent, followed by high-risk pregnancy (64.2\%), discharge (62.9\%), newborn care 
Table 2. Demographic and Obstetric Characteristics of Participants

$(N=97)$

\begin{tabular}{llc}
\hline Characteristics & Categories & $\mathrm{n}(\%)$ or \\
& & $\mathrm{M} \pm \mathrm{SD}$ \\
\hline Age (year) & & $33.4 \pm 4.0$ \\
Education & High school & $8(8.2)$ \\
& College & $89(91.8)$ \\
Monthly income & $<300$ & $19(19.6)$ \\
(10,000 won) & $300 \sim<400$ & $19(19.6)$ \\
& $400 \sim<500$ & $12(12.4)$ \\
& $\geq 500$ & $47(48.4)$ \\
Occupation & No & $38(39.2)$ \\
& Yes & $59(60.8)$ \\
Gestational age & $<37$ & $27(27.8)$ \\
(week) & $\geq 37$ & $70(72.2)$ \\
& & $36.5 \pm 4.6$ \\
Parity & Primipara & $55(56.7)$ \\
& Multipara & $42(43.3)$ \\
Reasons for & Natural delivery & $33(30.3)$ \\
admission & Induction & $16(14.7)$ \\
(n=109) & Cesarean section & $25(23.0)$ \\
& Preterm labor & $12(11.0)$ \\
& Gestational diabetes mellitus & $7(6.4)$ \\
& Preeclampsia & $7(6.4)$ \\
& Premature rupture of membrane & $5(4.6)$ \\
& Others & $2(1.8)$ \\
& & $2(1.8)$ \\
\hline
\end{tabular}

(59.8\%), delivery (54.0\%), and postpartum care (38.6\%). Among participants who received text messages for HiChart, 58 participants engaged fully $(16.5 \%)$ or partially $(43.3 \%)$, while 39 participants (40.2\%) did not engage with the HiChart educational content (Table 3). We examined the difference in participants' characteristics between engaged (fully or partially) and non-engaged women. There was a significant difference in parity $\left(x^{2}=4.57, p=.033\right)$. Multiparas $(n=20,34.5 \%)$ engaged with the HiChart education less than primiparas $(n=38,65.5 \%)$.

\section{Reasons for Not Engaging with HiChart}

The reasons participants did not engage with HiChart are shown in Figure 2. The most common reason was that participants "did not know what the text message was for" (26.1\%) followed by "did not have enough time to watch" (23.4\%), "had an internet connection problem (Wi-Fi)" (12.0\%), "thought the text massage was spam" (8.8\%), "already knew the educational content" (8.6\%), and "did not need it (education)" (5.5\%).

Several other reasons were reported by the patients for not engaging with HiChart. Some patients reported that they found it difficult to concentrate on the educational content during labor due to pain. Patients who underwent cesarean sections reported that they could not engage with HiChart because they underwent many tests before surgery and due to postoperative pain after surgery. Women with high-risk preg-

*Multiple answer.

$(N=97)$

Table 3. Engagement and Satisfaction by Participants' Characteristics

\begin{tabular}{|c|c|c|c|c|c|c|}
\hline \multirow{2}{*}{ Characteristics } & \multirow{2}{*}{ Categories } & Engaged $(n=58)$ & Not engaged $(n=39)$ & \multirow{2}{*}{$x^{2}$ or $\mathrm{t}(p)$} & Satisfaction $(n=58)$ & \multirow{2}{*}{ t or $F(p)$} \\
\hline & & $\mathrm{n}(\%)$ or $\mathrm{M} \pm \mathrm{SD}$ & $\mathrm{n}(\%)$ or $\mathrm{M} \pm \mathrm{SD}$ & & $\mathrm{M} \pm \mathrm{SD}$ & \\
\hline Total & & $58(59.8)$ & $39(40.2)$ & & $4.0 \pm 0.8$ & \\
\hline Age & & $32.78 \pm 3.55$ & $34.31 \pm 4.57$ & $1.86(.067)$ & & \\
\hline Education & $\begin{array}{l}\text { High school } \\
\geq \text { College }\end{array}$ & $\begin{array}{c}4(6.9) \\
54(93.1)\end{array}$ & $\begin{array}{r}4(10.3) \\
35(89.7)\end{array}$ & $0.35(.555)$ & $\begin{array}{l}3.8 \pm 0.5 \\
4.2 \pm 0.8\end{array}$ & $1.10(.277)$ \\
\hline $\begin{array}{l}\text { Monthly income } \\
\text { (10,000 won) }\end{array}$ & $\begin{array}{l}<300 \\
300 \sim<400 \\
400 \sim<500 \\
\geq 500\end{array}$ & $\begin{array}{c}13(22.4) \\
12(20.7) \\
5(8.6) \\
28(48.3)\end{array}$ & $\begin{array}{r}6(15.5) \\
7(17.9) \\
7(17.9) \\
19(48.7)\end{array}$ & $3.03(.552)$ & $\begin{array}{l}4.2 \pm 0.8 \\
4.4 \pm 0.7 \\
3.6 \pm 0.5 \\
4.2 \pm 0.9\end{array}$ & $1.10(.357)$ \\
\hline Occupation & $\begin{array}{l}\text { No } \\
\text { Yes }\end{array}$ & $\begin{array}{l}24(41.4) \\
34(58.6)\end{array}$ & $\begin{array}{l}14(35.9) \\
25(64.1)\end{array}$ & $0.29(.588)$ & $\begin{array}{l}4.2 \pm 0.9 \\
4.2 \pm 0.7\end{array}$ & $0.40(.693)$ \\
\hline $\begin{array}{l}\text { Gestational age } \\
\text { (week) }\end{array}$ & $\begin{array}{l}<37 \\
\geq 37\end{array}$ & $\begin{array}{l}14(24.1) \\
44(75.9)\end{array}$ & $\begin{array}{l}13(33.3) \\
26(66.7)\end{array}$ & $0.98(.322)$ & $\begin{array}{l}4.1 \pm 0.7 \\
4.2 \pm 0.9\end{array}$ & $0.20(.839)$ \\
\hline Parity & $\begin{array}{l}\text { Primipara } \\
\text { Multipara }\end{array}$ & $\begin{array}{l}38(65.5) \\
20(34.5)\end{array}$ & $\begin{array}{l}17(43.6) \\
22(56.4)\end{array}$ & $4.57(.033)$ & $\begin{array}{l}4.2 \pm 0.7 \\
4.2 \pm 1.0\end{array}$ & $0.08(.935)$ \\
\hline $\begin{array}{l}\text { Reasons for } \\
\text { admission }\end{array}$ & $\begin{array}{l}\text { Natural delivery } \\
\text { Induction } \\
\text { Cesarean section } \\
\text { Preterm labor } \\
\text { Others }\end{array}$ & $\begin{array}{r}22(37.9) \\
11(19.0) \\
10(17.2) \\
7(12.1) \\
8(13.8)\end{array}$ & $\begin{aligned} 11 & (28.2) \\
2 & (5.1) \\
14 & (35.9) \\
5 & (12.8) \\
7 & (18.0)\end{aligned}$ & $7.53(.110)$ & $\begin{array}{l}4.2 \pm 0.9 \\
4.3 \pm 0.9 \\
4.0 \pm 0.9 \\
4.1 \pm 0.7 \\
4.2 \pm 0.8\end{array}$ & $0.17(.953)$ \\
\hline
\end{tabular}




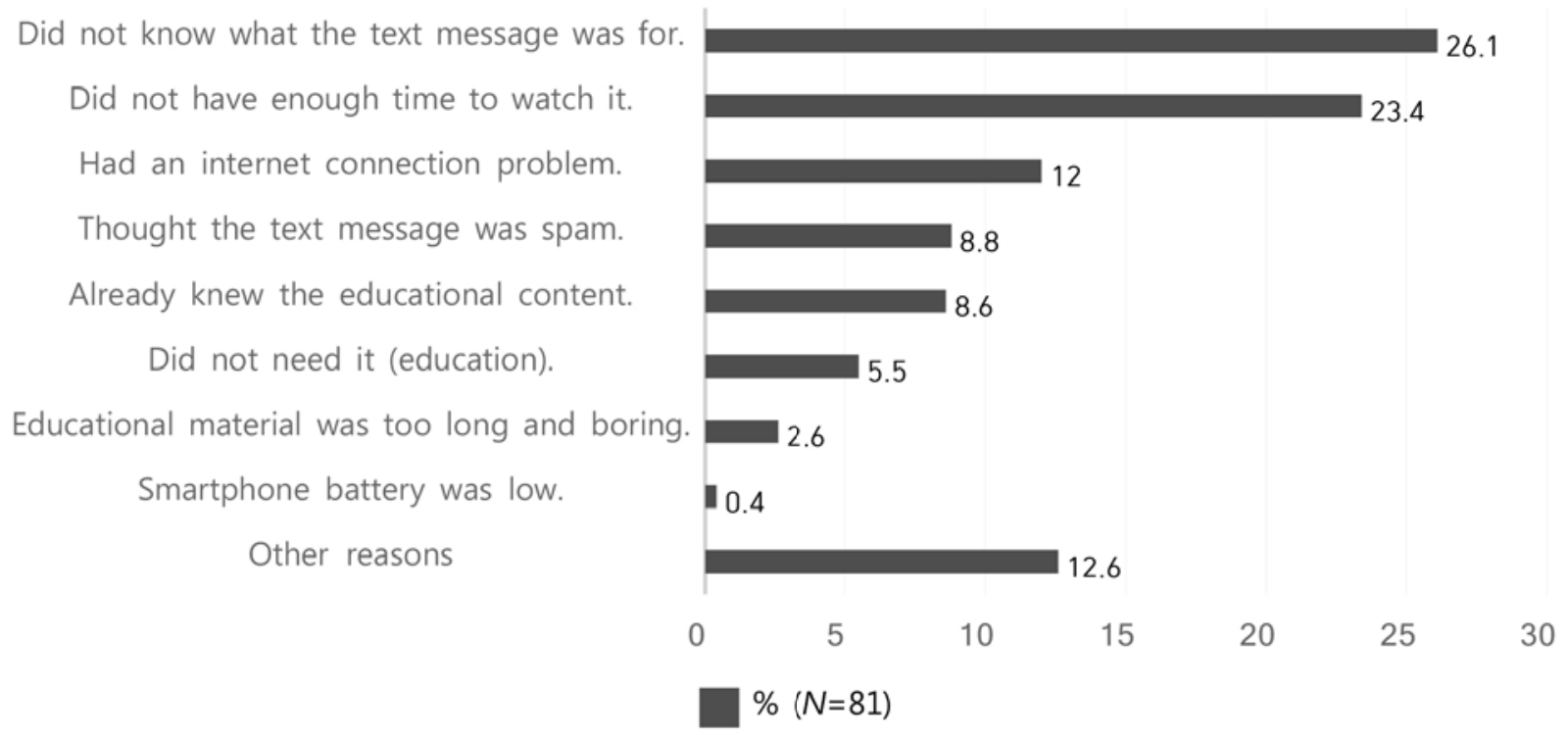

Figure 2. Reasons for not fully engaging with the HiChart content.

nancies stated they had to concentrate on their intensive treatment immediately after admission and needed time to adapt to their new circumstances. Some patients stated they had already obtained a brochure or information from their nurses before they received the HiChart messages. Some patients said that they engaged with HiChart only on the first day that they received a text message because they thought the text messages received on other days were the same as that received on the first day. Each text message URL contained a link to three to four HiChart segments; however, some patients said they watched only the first segment because they did not know other segments were available below. Patients who shared a room with other patients contained said that they immediately closed HiChart because they were concerned that the sound might bother other pregnant women. Additionally, some participants asked for the scope of the educational content to be broadened, with possible topics including as coping with infant emergencies, bottle feeding, breast care, postpartum care, and information about the neonatal intensive care unit.

\section{Satisfaction}

Those who engaged at least once with any HiChart content $(n=58)$ responded to the satisfaction questions. The mean score of overall satisfaction with HiChart was $4.0 \pm 0.8$. Meanwhile, the mean score for "ease of understanding" was $4.5 \pm 0.7$, that for "sufficiency of information" was $4.4 \pm 0.7$, and that for "convenience" was $4.0 \pm 0.8$ with possible scores ranging from
1 to 5 .

\section{DISCUSSION}

This study aimed to examine pregnant women's engagement and satisfaction with mobile web-based education (HiChart). Among the participants who received the HiChart service, only $59.8 \%$ engaged with the mobile web-based education program fully or partially. However, the patients who used HiChart reported relatively high satisfaction.

Studies have reported that the quality of online health information varies greatly $[23,24]$, indicating that reliable sources of education are needed. Despite the availability of reliable educational materials (HiChart), the engagement rate was low in this study. One of the main reason participants did not use the HiChart education program was that they were not aware of it. Therefore, nurses should promote this service by informing the patients regarding the text messages and when and how they can engage with HiChart. It has become more common for inpatients to use eHealth or mHealth educational services. For instance, pregnant women undergoing a cesarean section were in favor of adding mobile applications to their perioperative management [25]. Furthermore, patients tend to engage in their care and to optimize their hospital experience through use of their mobile devices [26]. This indicates that mHealth education could be utilized as an alternative or supportive method for inpatients.

Women who undergo a cesarean section tend to have longer recovery times and experience greater fatigue due to post- 
operative pain than women who delivered vaginally [27]. Since it may be difficult for such patients to watch the HiChart videos due to postoperative pain and fatigue, sending text messages about the HiChart educational program to patients at the outpatient clinic should be an option and could be offered as part of the continuum of care.

In the present study, some high-risk pregnant women found it difficult to concentrate on the HiChart education materials due to their unstable and stressful situations amidst sudden hospitalization. Thus, many patients did not believe they had time to watch the mobile web-based educational videos. However, in a study on satisfaction and mental wellbeing after internet-based cognitive-behavioral stress management, providing information significantly reduced stress and anxiety in pregnant women experiencing preterm labor and increased maternal self-confidence [20]. There was a significant drop in stress after listening to material on a stress coping app for hospitalized pregnant women at risk for preterm birth [28]. Although high-risk pregnant women should be strongly encouraged to engage with the HiChart education program, it would be better to send them text messages about HiChart after stabilizing their condition and reducing their anxiety, rather than immediately after an emergency admission. Alternatively, HiChart could be first sent to the patient's guardian with encouragement to share the information with the patient later.

In this study, multiparas engaged with the HiChart service less than primiparas. This implies that women who are experiencing first-time pregnancies may have more educational needs. In addition, a study reported that first time mothers' infant care education needs were higher than those of multipara mothers [29]. Thus, it is essential to pay more attention to first-time mothers, and it could be helpful to utilize smartphone-based education as a supportive method.

Participants' overall satisfaction with HiChart education was high, indicating that the patients found the mobile webbased educational material easy to understand, considered the information sufficient, and appreciated the convenience of the educational method using a smartphone. Women who were more willing to participate in mobile web-based education experienced greater satisfaction than those who were less willing to participate [21]. Although most participants who engaged with the web-based education provided a favorable evaluation of the HiChart service, some participants had suggestions for improvement, including issues related to internet access. Data usage is very high when using a smartphone to view mobile web-based educational videos. In fact, some patients stated they did not engage with the HiChart educational materials because the free Wi-Fi connection did not work well. Several patients stopped watching while playing the content due to a lack of personal mobile data. Therefore, it is important to create a user-friendly environment by allowing free use of wireless internet in patient rooms and informing the patients that free wireless internet is available. Additionally, some patients did not engage with the mobile webbased education because of their concerns about the noise disturbance when playing the educational content in a shared room. Thus, providing services and products such as earphones for pregnant women who share a room would be helpful. In addition, covering a broader range of educational content, corresponding to participants' requests for information on topics including coping with infant emergencies and information about the neonatal intensive care unit, would help them to better understand what to expect and meet the users' expectations. Preterm birth might exert a negative effect on the mothers' well-being [30]. Nursing care based on women's needs would increase the likelihood of women having a positive experience in their transition to motherhood.

This study has a few aspects that distinguish it from previous studies. First, previous studies on mobile web-based pregnancy health care education programs were mostly conducted in community settings or outpatient clinics, and most of their content was limited to prenatal care. In contrast, the current study was conducted among patients who were hospitalized for obstetric care. Second, this study focused on engagement and satisfaction with the educational materials among inpatient pregnant women, topics on which few studies have been conducted.

This study has several limitations. First, the generalizability of the results is limited because this was a cross-sectional descriptive study conducted at a single general hospital, in a country where mobile internet service is ubiquitous. Second, the measurement of participants' engagement with mobile web-based education was based on self-reports rather than objective assessments. Third, a small sample size was a limitation of this study. Finally, we only examined the users' engagement with the educational service. Thus, we suggest future research with a larger sample size to examine the impacts of the HiChart service on maternal and fetal outcomes. It should be noted that, despite all these limitations, this study adds to existing knowledge by providing items for improvement when utilizing mobile web-based education for inpatient pregnant women to provide high-quality of care and education.

\section{CONCLUSION}

In the present study, participants' engagement and satisfaction with the HiChart mobile web-based education service were evaluated among pregnant women admitted to a general hospital. The participants' satisfaction with the Hi-Chart 
educational materials used in this study was generally high, but the engagement of participants with the service was low and not all patients received the text messages, even though HiChart was a part of routine nursing care.

First of all, to increase the engagement rate of pregnant women with mobile web-based education, nurses should inform pregnant women that an educational web link was sent to their smartphone and encourage them to engage with the mobile web-based education program. Users' satisfaction could be improved and their needs met by providing comprehensive information regarding web-based education, more educational content on topics they requested, and better environmental support for web users.

\section{Conflict of interest}

No existing or potential conflict of interest relevant to this article was reported.

\section{REFERENCES}

1. Almalik MMA, Mosleh SM. Pregnant women: What do they need to know during pregnancy? A descriptive study. Women and Birth. 2017;30(2):100-106.

https://doi.org/10.1016/j.wombi.2016.09.001

2. Wang HJ, Kim IO. Effects of a mobile web-based pregnancy health care educational program for mothers at an advanced maternal age. Journal of Korean Academy of Nursing. 2015;45(3):337-346. https://doi.org/10.4040/jkan.2015.45.3.337

3. Downe S, Finlayson K, Tunçalp Ö, Metin Gülmezoglu A. What matters to women: A systematic scoping review to identify the processes and outcomes of antenatal care provision that are important to healthy pregnant women. BJOG: An International Journal of Obstetrics and Gynaecology. 2016;123(4):529-539.

https://doi.org/10.1111/1471-0528.13819

4. Kim MY, Kim GS, Kim S, Lee HJ. Participation in prenatal education, knowledge and attitude related to delivery, postpartum care, newborn care in nulliparous women. Korean Journal of Women Health Nursing. 2016;22(3):139-150.

https://doi.org/10.4069/kjwhn.2016.22.3.139

5. Carolan M, Frankowska D. Advanced maternal age and adverse perinatal outcome: A review of the evidence. Midwifery. 2011;27 (6):793-801. https://doi.org/10.1016/j.midw.2010.07.006

6. Pugh MA, Revell MA. Using online materials for prenatal education: The good, the bad and the ugly. International Journal of Childbirth Education. 2011;26(4):9-13.

7. Serçekuş P, Başkale H. Effects of antenatal education on fear of childbirth, maternal self-efficacy and parental attachment. Midwifery. 2016;34:166-172. https://doi.org/10.1016/j.midw.2015.11.016

8. Cummiskey M. There's an app for that smartphone use in health and physical education. Journal of Physical Education, Recreation and Dance. 2011;82(8):24-30.

https://doi.org/10.1080/07303084.2011.10598672

9. Gao LL, Larsson M, Luo SY. Internet use by Chinese women seeking pregnancy-related information. Midwifery. 2013;29(7):730-735. https://doi.org/10.1016/j.midw.2012.07.003

10. Sayakhot $\mathrm{P}$, Carolan-Olah M. Internet use by pregnant women seeking pregnancy-related information: A systematic review. BMC Pregnancy and Childbirth. 2016;16:65.

https://doi.org/10.1186/s12884-016-0856-5

11. Lee $Y$, Moon M. Utilization and content evaluation of mobile applications for pregnancy, birth, and child care. Healthcare Informatics Research. 2016;22(2):73-80.

https://doi.org/10.4258/hir.2016.22.2.73

12. Wallwiener S, Müller M, Doster A, Laserer W, Reck C, PauluschkeFröhlich J, et al. Pregnancy eHealth and mHealth: User proportions and characteristics of pregnant women using Web-based information sources-A cross-sectional study. Archives of Gynecology and Obstetrics. 2016;294(5):937-944.

https://doi.org/10.1007/s00404-016-4093-y

13. Oliveira-Ciabati L, Vieira CS, Franzon ACA, Alves D, Zaratini FS, Braga GC, et al. PRENACEL - A mHealth messaging system to complement antenatal care: A cluster randomized trial. Reproductive Health. 2017;14:146.

https://doi.org/10.1186/s12978-017-0407-1

14. Lau YK, Cassidy T, Hacking D, Brittain K, Haricharan HJ, Heap M. Antenatal health promotion via short message service at a midwife obstetrics unit in South Africa: A mixed methods study. BMC Pregnancy and Childbirth. 2014;14:284. https://doi.org/10.1186/1471-2393-14-284

15. Nørgaard SK, Nichum VL, Barfred C, Juul HM, Secher AL, Ringholm L, et al. Use of the smartphone application "Pregnant with Diabetes". Danish Medical Journal. 2017;64(11):A5417.

16. Skar JB, Garnweidner-Holme LM, Lukasse M, Terragni L. Women's experiences with using a smartphone app (the Pregnant+App) to manage gestational diabetes mellitus in a randomised controlled trial. Midwifery. 2018;58:102-108.

https://doi.org/10.1016/j.midw.2017.12.021

17. Feroz A, Perveen S, Aftab W. Role of mHealth applications for improving antenatal and postnatal care in low and middle income countries: A systematic review. BMC Health Services Research. 2017;17:704. https://doi.org/10.1186/s12913-017-2664-7

18. Jackson GP, Robinson JR, Ingram E, Masterman M, Ivory C, Holloway $\mathrm{D}$, et al. A technology-based patient and family engagement consult service for the pediatric hospital setting. Journal of the American Medical Informatics Association. 2018;25(2):167-174. https://doi.org/10.1093/jamia/ocx067

19. Finkelstein J, Cha EM. Using a mobile app to promote smoking cessation in hospitalized patients. JMIR Mhealth and Uhealth. 2016;4(2):e59. https://doi.org/10.2196/mhealth.5149 
20. Scherer S, Alder J, Gaab J, Berger T, Ihde K, Urech C. Patient satisfaction and psychological well-being after internet-based cognitive behavioral stress management (IB-CBSM) for women with preterm labor: A randomized controlled trial. Journal of Psychosomatic Research. 2016;80:37-43.

https://doi.org/10.1016/j.jpsychores.2015.10.011

21. Baltierra NB, Muessig KE, Pike EC, LeGrand S, Bull SS, Hightow-Weidman LB. More than just tracking time: Complex measures of user engagement with an internet-based health promotion intervention. Journal of Biomedical Informatics. 2016; 59:299-307. https://doi.org/10.1016/j.jbi.2015.12.015

22. Martin T. Assessing mHealth: Opportunities and barriers to patient engagement. Journal of Health Care for the Poor and Underserved. 2012;23(3):935-941. https:// doi.org/10.1353/hpu.2012.0087

23. Kennedy RA, Mullaney L, Reynolds CM, Cawley S, McCartney DM, Turner MJ. Preferences of women for web-based nutritional information in pregnancy. Public Health. 2017;143:71-77. https://doi.org/10.1016/j.puhe.2016.10.028

24. Son HM, Je M, Sohn YS. Quality evaluation of online health information related to young child. Child Health Nursing Research. 2018;24(1):91-100. https://doi.org/10.4094/chnr.2018.24.1.91

25. Ke JXC, George RB, Wozney L, Chorney JL. Patient-centred perioperative mobile application in cesarean delivery: Needs assess- ment and development. Canadian Journal of Anesthesia. 2019. https://doi.org/10.1007/s12630-019-01392-x

26. Ludwin S, Greysen SR. Use of smartphones and mobile devices in hospitalized patients: Untapped opportunities for inpatient engagement. Journal of Hospital Medicine. 2015;10(7):459-461. https://doi.org/10.1002/jhm.2365

27. Lavand'homme P. Long-term problems and chronic pain after Caesarean section. In: Capogna G, editor. Anesthesia for Cesarean section. Switzerland: Springer, Cham; 2017. p. 169-182. https://doi.org/10.1007/978-3-319-42053-0_12

28. Jallo N, Thacker LRI, Menzies V, Stojanovic P, Svikis DS. A stress coping app for hospitalized pregnant women at risk for preterm birth. MCN: The American Journal of Maternal/Child Nursing. 2017;42(5):257-262. https://doi.org/10.1097/NMC.0000000000000355

29. Koh HJ, Lim KH. A comparison of the educational needs of the mothers' for the infant care between primipara and multipara. Korean Journal of Child Health Nursing. 2002;8(2):217-228.

30. Trumello C, Candelori C, Cofini M, Cimino S, Cerniglia L, Paciello $\mathrm{M}$, et al. Mothers' depression, anxiety, and mental representations after preterm birth: A study during the infant's hospitalization in a neonatal intensive care unit. Frontiers in Public Health. 2018;6:359. https://doi.org/10.3389/fpubh.2018.00359 